\title{
WATER UPTAKE STRATEGIES OF TYPICAL BROADLEAF AND CONIFEROUS TREES IN THE LOESS PLATEAU MOUNTAIN AREA OF NORTHERN CHINA
}

\author{
ZHAO, W. W. - HAN, Y. Z. ${ }^{*}-$ LIANG, W. J. ${ }^{*}-$ WEI, X. \\ College of Forestry, Shanxi Agricultural University, Taigu 030801, China \\ (e-mail/phone: 18846321311@163.com/+86-132-8366-3065-W.W. Zhao) \\ *Corresponding authors \\ e-mail/phone: hanyouzhi@sxau.edu.cn/+86-135-1354-4398 (Y. Z. Han); \\ liangwenjun123@163.com/+86-199-3542-3559(W. J. Liang) \\ (Received $1^{\text {st }}$ Apr 2021; accepted $8^{\text {th }}$ Jul 2021)
}

\begin{abstract}
Poor precipitation in the Loess Plateau area may significantly influence water uptake strategies of the plants growing there. The water sources of these trees have not been studied to date. We investigated the impacts of precipitation (before and after) on the water uptake strategies of typical broadleaf and coniferous trees in the Loess Plateau mountain area of northern China by using hydrogen and oxygen stable isotope techniques. Our results indicated that water sources of these two tree types varied before and after rainfall. Robinia pseudoacacia, a broadleaf tree, absorbed water mostly from the $30-40 \mathrm{~cm}(57.8 \%)$ soil layer before precipitation and from the $20-30 \mathrm{~cm}(58.5 \%)$ soil layer after precipitation. However, Pinus tabuliformis, a coniferous tree, mainly absorbed water from $20-30 \mathrm{~cm}$ (24.9\%) and $10-20 \mathrm{~cm}(21.6 \%)$ soil layers before precipitation and from $0-10 \mathrm{~cm}(39.8 \%)$ and $10-20 \mathrm{~cm}$ $(44 \%)$ soil layers after precipitation. Moreover, the herbaceous plants within the broadleaved forests had a higher community complexity according to filed investigation. Thus, $R$. pseudoacacia and P. tabuliformis exhibited peculiar difference in terms of water uptake, indicating that they are suitable to grow together as forest vegetation in arid and semi-arid areas. Overall, our results provided vital information for sustainable afforestation management in the Loess Plateau mountain area of northern China.
\end{abstract}

Keywords: precipitation, soil water, xylem water, plant water source, water uptake, Iso-source model

\section{Introduction}

Plants play a vital role in the soil-plant-atmosphere continuum. Their water usage can be impacted by the quantity of the global water resources (Flanagan et al., 2010; Jackson et al., 1999; Williams and Ehleringer, 2000; Yang et al., 2010; Zhan et al., 2019). Most forests are universally distributed in the Loess Plateau area because of the limitations of geographical conditions (Cheng et al., 2006), such as thin soils, high distribution of gravel and frequent droughts. The Loess Plateau area is widely distributed in the Shanxi area, where water shortage, soil erosion, and drought events occur more frequently. Meanwhile, water scarcity is a crucial environmental issue globally; its main causing factor is evapotranspiration exceeding precipitation with the climate change. This can cause considerable harm to ecologies including fragile ecosystems of the Loess Plateau (Boyer and J., 1982; Knapp et al., 2001; Liu et al., 2017). Meanwhile, water, as one of the influential ecological factors, can restrict vegetation coverage, species richness, vegetation growth, biomass, and diversity in fragile ecosystems regions; thus, water has a vital role in the distribution of forest vegetation (Bai et al., 2004; Chang et al., 2019; Gao et al., 2011; Heras et al., 2011). In the soil-root-xylem pathway, absorbed water is a major component in hydrological processes. Hence, it is important to investigate the water distribution characteristics and uptake patterns of typical trees in the soil-xylem-root 
pathway when water availability is limited. Whether such trees can coexist in the Loess Plateau region needs to be investigated.

Precipitation is the fundamental water source for the Loess Plateau forest ecosystems; however, the seasonal drought causes long-term soil water insufficiency, and this may be a critical factor for limited tree distribution and growth in this area (Zhai et al., 2014; Zhang et al., 2011). Limited input of water can aggravate competition for water among tree species, affecting the physiological activities of trees (Liu et al., 2018). Precipitation might be a key element influencing the water sources for plants. Low precipitation can moisten the 0-20 cm soil layer, but the water in this layer is easily lost through evaporation (Dunkerley, 2015). Meanwhile, the quality and quantity of soil water are primarily affected by atmospheric precipitation because the source of soil water is precipitation. The characteristics of hydrogen and oxygen isotopes of surface water exhibit a relatively consistent and proportionate change with the shift in the characteristics of those of precipitation. However, the stable isotope of soil water is affected by many factors such as the stable isotope of atmospheric precipitation, surface evaporation, and vertical movement of water in soil. The water sources that plants can use include precipitation, soil water, runoff, and groundwater under natural conditions. According to the different distribution of these water sources, many plants have developed a "plasticity dimorphic root system," which can obtain water from surface soil layers, and if required, acquire it from groundwater or further deeper soil layers (Evaristo et al., 2016; Wu et al., 2015; Yang et al., 2011). The responses of plants to rainfall depend partly on the features of precipitation, as well as on the structure of trees, root morphology, and physiological characteristics (Dai et al., 2015; Poot and Lambers, 2008).

Stable isotopes of water $\left(\mathrm{D}\right.$ and ${ }^{18} \mathrm{O}$ ), as tracer elements, have been widely used in hydrology research, which nowadays can be applied to interpret the specific information about water circulation and to distinguish the sources of water uptake and understand their connections (Deng et al., 2016; Gurumurthy et al., 2015; Busato et al., 2019; Wood, 2011; $\mathrm{Xu}$ et al., 2019). The water source of trees can be determined by comparing the stable isotopic values for $\delta^{2} \mathrm{H}$ and $\delta^{18} \mathrm{O}$ obtained from the xylem with those of all latent water sources (Dawson and Pate, 1996; Phillips and Gregg, 2003). In addition, before transpiration of roots and leaves, isotopic fractionation does not occur during water absorption and transportation, which occurs in the water vapor cycle. Therefore, this new method of stable isotope technology has been widely used in hydrology (Gazis and Feng, 2004; Liu et al., 2017). Moreover, some studies have reported that by using this method and analyzing the plant xylem water and soil water for $\delta^{2} \mathrm{H}$ and $\delta^{18} \mathrm{O}$ values, all potential water sources of forest in the Loess Plateau area can be determined (Caldweli, 2005; Kambatuku et al., 2013; Moreno-Gutiérrez et al., 2015). For instance, during the seasonal drought in the Loess Plateau district, when soil water in the shallow layer is limited, more plants absorb water from the $80-100 \mathrm{~cm}$ soil layer or further deeper layers by using their deep root systems (Quesada et al., 2008; Liu et al., 2017; Romero-Saltos et al., 2005; West et al., 2008). Therefore, by altering root morphology, broadleaf and coniferous plants have adapted to variable soil water content (SWC) during drought (Ianovici et al., 2020).

Pinus tabuliformis and Robinia pseudoacacia are typical coniferous and broadleaf trees, respectively, in the mountain areas of north China. Water scarcity and lack of soil precipitation are the common problems in the Loess Plateau. Extreme rainfall events will be common in there (Li et al., 2013; Wu et al., 2016). Nonetheless, the water sources of plants would vary because of the diverse characteristics of rainfall. At present, though 
major surveys have been conducted in several fragile areas, the water uptake strategies of typical broadleaf and coniferous tree species during the growing and wet season in the Loess Plateau mountain area of Shanxi before and after precipitation are unknown. Therefore, the objectives of this study were to ( $i$ ) investigate the water source of $P$. tabuliformis and $R$. pseudoacacia and establish the relationship among precipitation, soil water, xylem water, natural spring water, and groundwater in different water distribution system, (ii ) explore whether there is competition for water source between these two tree species and whether there is a possibility of coexistence, and (iii) determine the factors affected by the varying water uptake strategies of these trees. We used the hydrogen and oxygen stable isotope techniques to analyze the $\delta \mathrm{D}$ and $\delta^{18} \mathrm{O}$ isotope ratio values in groundwater, soil water, spring water, and xylem water, and further studied their response to temporal variations in rainfall. This study may provide valuable information for forest management in this area.

\section{Materials and methods}

\section{Study site}

The study area (Fig. 1) was located in Caijiachuan Catchment, Ji County, Shanxi Province, in the Loess Plateau Gully Region near the Yellow River $\left(110^{\circ} 40^{\prime}-110^{\circ} 48^{\prime} \mathrm{E}\right.$, $\left.36^{\circ} 14^{\prime}-36^{\circ} 18^{\prime} \mathrm{N}\right)$. Mean annual temperature, mean illumination hours, mean annual precipitation, and mean annual evaporation are $11^{\circ}, 2563.8 \mathrm{~h}, 571 \mathrm{~mm}$, and $1729 \mathrm{~mm}$, respectively (Mei et al., 2018). The elevation ranges from 393 to $1820 \mathrm{~m}$. Most of the terrain of the base is a typical erosive terrain of the Loess Plateau. The soil type is cinnamon soil. The forest plant zone is a gradation from the cinnamon soil broadleaf forest zone to the forest steppe zone in the warm temperate zone (Wang et al., 2018; Wei et al., 2018). The natural vegetation in the study area includes herbs and shrubs such as Carex rigescens, Artemisia caruifolia, Rubus parvifolius, Rubia cordifolia var. cordifolia, Metaplexis japonica, Fallopia multiflora, Patrinia scabiosifolia, Potentilla chinensis var. chinensis, Chrysanthemum indicum, Artemisia gmelinii, Erigeron bonariensis, Saussurea japonica, and Bupleurum chinense.

\section{Experimental design}

We investigated the main dominant tree species in this study area (0.5 ha). Further, two sample plots for fixed observation were established by selecting the typical plantation with good growth. The two sample plots (with an area of $40 \times 40 \mathrm{~m}^{2}$ ) contained the $P$. tabuliformis and $R$. pseudoacacia, respectively (Table 1 ). A distance of $100 \mathrm{~m}$ was maintained between the experimental plots to eliminate the edge effect. In each plot, 10 small quadrats $(1 \mathrm{~m} \times 1 \mathrm{~m})$ were selected for the investigation of undergrowth vegetation. The following contents were included in the survey: species, height, growth, and distribution of herbs. The significant value was used to measure diversity indices such as Simpson index, Shannon-Wiener index, and Pielou index.

Sampling of precipitation, branches, soil, natural spring water, groundwater, and forest litter

Three standard, similarly well-growing trees without artificial disturbance were selected in the two plots. The samples were collected in this area from August 11 to 
August 20 in 2020. Precipitation samples were collected immediately after a rainfall to reduce evaporation effects. Two simple rainwater collectors were installed to collect rainfall samples in an unobstructed area. A plastic funnel containing a table tennis ball was placed atop the collector. Precipitation samples were collected after each rainfall of greater than $2 \mathrm{~mm}$. The precipitation samples in the forest were collected under the forest; the precipitation samples outside the forest were collected in an open area where had a distance of $20 \mathrm{~m}$ from the sample plots. These samples were rapidly placed into clean plastic centrifuge tubes $(50 \mathrm{~mL})$, sealed, immediately stored in a refrigerator, and frozen at $-4{ }^{\circ} \mathrm{C}$ at the laboratory until further testing. The samples were collected in triplicates from each of the two rainfall collectors.

Three soil sampling points were selected near the standard trees, and the soil samples were collected in triplicates at the depths of 0-10, 10-20, 20-30, 30-40, and 40-60 cm using soil drilling. Also, we recorded the rooting depth of these two species $(R$. pseudoacacia: $10-50 \mathrm{~cm}, P$. tabuliformis: $0-40 \mathrm{~cm}$ ). Further, a portion of each soil layer was placed in clean plastic centrifuge tubes $(50 \mathrm{~mL})$, sealed with parafilm $\mathrm{M}^{\circledR}$ immediately, and frozen at $-4{ }^{\circ} \mathrm{C}$ in the laboratory to avoid evaporation fractionation. Another portion of each soil layer was placed in an aluminum box, weighed, and dried in a baking oven at $105^{\circ} \mathrm{C}$ for 2 days.
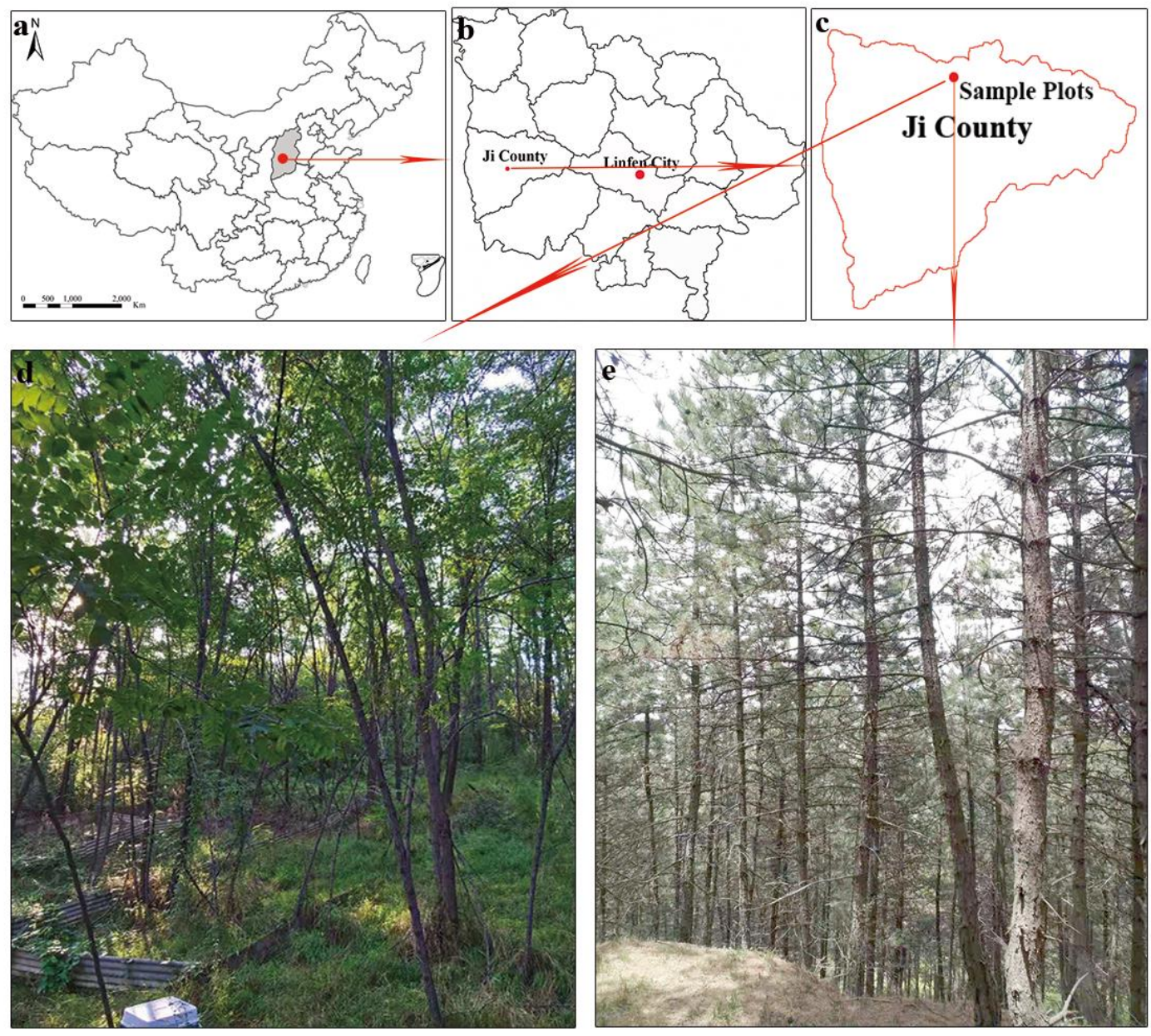

Figure 1. Location map of study area in Ji County (Caijiachuan Catchment) (c), Linfen City (b), northern China (a). (d), (e) locations of experimental sites on R. pseudoacacia forest (Shidaowan) and P. tabuliformis forest (Yousongbao), respectively 
Table 1. Basic status of the sample plots, sampled tree species and main plant species undergrowth vegetation

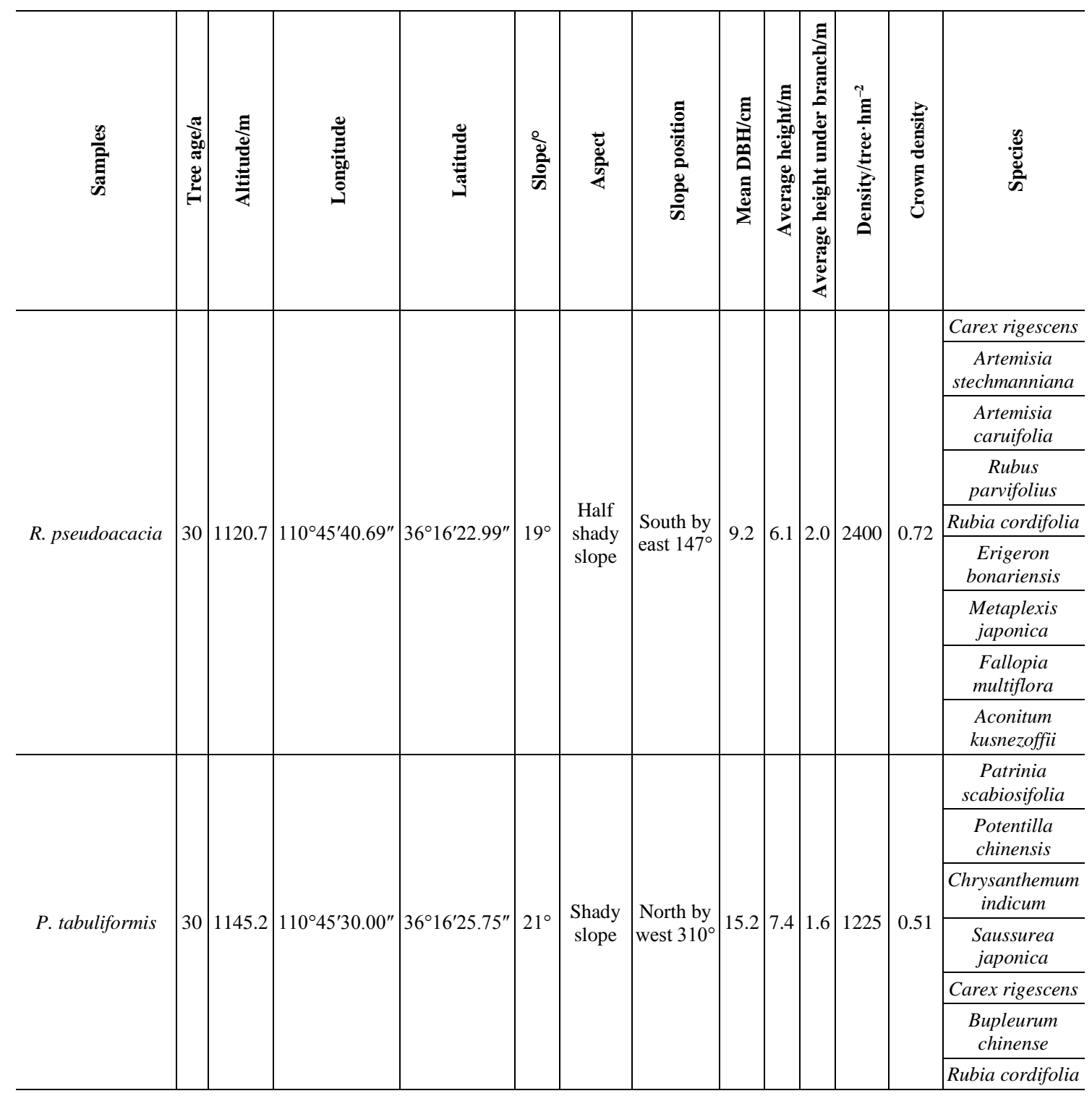

Suberized (Ripe, non-green and diameter $0.3-0.6 \mathrm{~cm}$ ) branches in the selected five standard trees were collected from each plot by a pair of scissors in triplicates. Barks of all xylem samples were immediately removed using a knife, and further, the xylem samples were placed into clean plastic centrifuge tubes $(50 \mathrm{~mL})$, sealed, immediately stored in a refrigerator, frozen at $-4{ }^{\circ} \mathrm{C}$ in the laboratory to avoid evaporation fractionation. The natural spring water sampling plot was located $1 \mathrm{~km}$ away from the sampling trees. The groundwater samples were collected in triplicates after different precipitation events near the sampling plots; and the depth of groundwater was below $150 \mathrm{~cm}$.

Furthermore, the three small sampling points of $1 \mathrm{~m} \times 1 \mathrm{~m}$ were established in these sampling plots. The samples of undecomposed and semi-decomposed litters for these two species were collected. The impurities were removed, and the litters were placed in bags and weighed. After taking the collected litters to the laboratory, water holding 
capacity was assessed Xuede et al. (2021). All the samples were collected before precipitation except for precipitation samples; and all the samples were also performed the first-day sampling after rainfall event.

\section{Meteorological data collection}

Two small mobile automatic weather stations (HOBO, U30-NRC, USA) were set up in the study area to record meteorological data and precipitation (Fig. 2). Stable isotopic values and data of rainfall and basic precipitation in China were collected from the Global Network of Isotopes in Precipitation (GNIP) (https://nucleus.iaea.org/wiser/index.aspx).

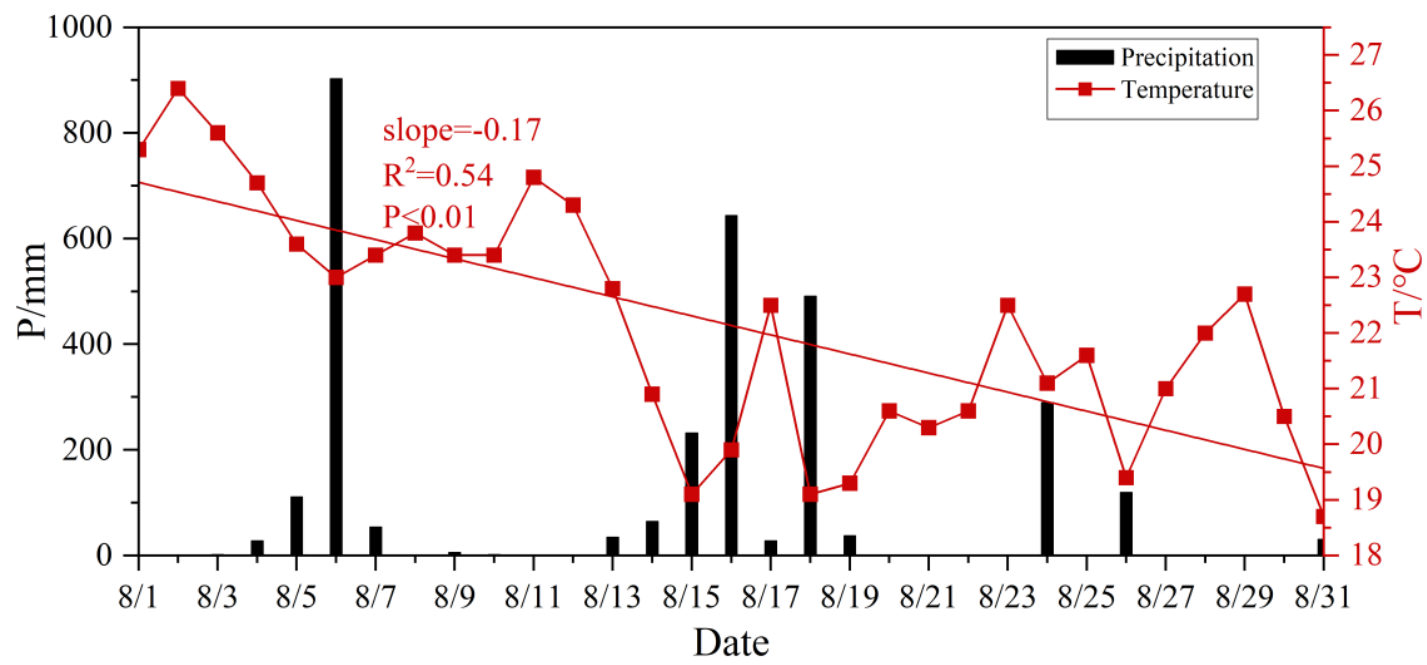

Figure 2. The variation characteristics of precipitation and temperature in August 2020. $P$ indicates precipitation; $T$ indicates temperature. The red line indicate the linear regression equation of precipitation

\section{Hydrogen and oxygen isotopes analysis}

Soil water and xylem water were fully extracted using an automatic vacuum condensation extraction system (LI-2100) (frozen with liquid nitrogen and evacuated under 1 atm of sub-atmospheric pressure). After extraction, the water samples were filtered and then stored at $-4{ }^{\circ} \mathrm{C}$ until further analyses. Using a liquid water isotope analyzer (LGR DLI-100, USA) (Liu et al., 2019), the D and ${ }^{18} \mathrm{O}$ isotopic values of natural spring water, precipitation, xylem water, and soil water were measured. The measurement accuracy of the instrument was $\pm 0.3 \%$ for $\delta \mathrm{D}$ and $\pm 0.1 \%$ for $\delta^{18} \mathrm{O}$ (Liu et al., 2020). The isotopic values can be calculated by Equation 1:

$$
\delta^{2} \mathrm{H}\left(\text { or } \delta^{18} \mathrm{O}\right)=\left(\frac{\mathrm{R}_{\mathrm{sample}}}{\mathrm{R}_{\text {standiarl }}}-1\right) \times 1000 \%
$$

In Equation 1, $\mathrm{R}_{\text {standard }}$ and $\mathrm{R}_{\text {sample }}$ represent the isotope ratios of $\left({ }^{2} \mathrm{H} / \mathrm{H}\right.$ or $\left.{ }^{18} \mathrm{O} /{ }^{16} \mathrm{O}\right)$ for all samples and the standard (VSMOW), respectively.

The d-excess can be calculated by Equation 2:

$$
\text { d-excess }=\delta^{2} \mathrm{H}-\delta^{18} \mathrm{O}
$$


The samples were collected in August 2020. A total of 20 precipitation samples, 120 soil water samples, 120 soil samples, 18 groundwater samples, and 30 xylem water samples were collected. SWC was calculated by Equation 3:

$$
\text { SWC }(\%)=\left(m-m_{d}\right) / m_{d} \times 100
$$

In Equation 3, $\mathrm{m}$ is soil water quantity $(\mathrm{kg})$ and $\mathrm{m}_{\mathrm{d}}$ is soil dry mass $(\mathrm{kg})$.

\section{Data analysis}

In this study, the multi-source model (Iso-Source) was used to quantify the contribution ratio of water sources for plant species (Gannes et al., 1998). The soil layers with similar isotopic values were merged together based on isotope mass conservation. The $\delta^{2} \mathrm{H}$ and $\delta^{18} \mathrm{O}$ values of precipitation, soil $(0-60 \mathrm{~cm})$ water, xylem water, and natural spring water were calculated using this model to improve the calculation accuracy. The formula for calculating the isotopic contribution ratios can be given as Equations 4 and 5:

$$
\begin{gathered}
\delta \mathrm{E}_{\mathrm{T}}=\mathrm{r}_{1} \delta \mathrm{E}_{\mathrm{s} 1}+\mathrm{r}_{2} \delta \mathrm{E}_{\mathrm{s} 2}+\mathrm{r}_{3} \delta \mathrm{E}_{\mathrm{s} 3}+\mathrm{r}_{4} \delta \mathrm{E}_{\mathrm{s} 4}+\mathrm{r}_{5} \delta \mathrm{E}_{\mathrm{s} 5}+\mathrm{r}_{6} \delta \mathrm{E}_{\mathrm{s} 6}+\mathrm{r}_{7} \delta \mathrm{E}_{\mathrm{s} 7}+\mathrm{r}_{8} \delta \mathrm{E}_{\mathrm{s} 8} \\
\mathrm{r}_{1}+\mathrm{r}_{2}+\mathrm{r}_{3}+\mathrm{r}_{4}+\mathrm{r}_{5}+\mathrm{r}_{6}+\mathrm{r}_{7}+\mathrm{r}_{8}=1
\end{gathered}
$$

In Equations 4 and 5, $\delta \mathrm{E}_{\mathrm{T}}$ is either the $\delta^{2} \mathrm{H}$ or the $\delta^{18} \mathrm{O}$ value in the branch water. The $\mathrm{S}_{1}-\mathrm{S}_{8}$ are the sources of water from $0-10,10-20,20-30,30-40$, and $40-60 \mathrm{~cm}$ soil layers; precipitation; groundwater and natural spring, respectively. Moreover, $\mathrm{r}_{1}-\mathrm{r}_{8}$ are the isotopic contribution ratios of $\mathrm{S}_{1}-\mathrm{S}_{8}$ for all potential branch water absorption.

\section{Results}

\section{Comparison of forest litter and characteristics of R. pseudoacacia and P. tabuliformis}

Litter layer is an important layer for water conservation in woodland, which plays an imperative role in intercepting precipitation, inhibiting soil water evaporation, and increasing soil water infiltration. We investigated the properties of litters in the forest. The average thickness of litter, the maximum water holding capacity, natural moisture content, natural moisture, storage capacity, and modified interception of $P$. tabuliformis and $R$. pseudoacacia were 1.6 and $0.8 \mathrm{~cm}, 12.87$ and $8.35 \mathrm{t} \cdot \mathrm{hm}^{-2}, 4.43$ and $1.68 \mathrm{~g} \mathrm{~cm}^{-3}$, $165 \%$ and $50 \%, 1.16$ and $0.77 \mathrm{t} \cdot \mathrm{hm}^{-2}$, and 6.51 and $5.41 \mathrm{t} \cdot \mathrm{hm}^{-2}$, respectively (Table 2). The maximum water holding capacity and water holding retention of $R$. pseudoacacia were higher than those of $P$. tabuliformis $\left(12.87\right.$ and $8.35 \mathrm{t} \cdot \mathrm{hm}^{-2}$ and $475.50 \%$ and $273.00 \%$, respectively).

\section{Variation of herb in two sample plots}

The diversity of the plant community can reflect the type of community structure. Great differences were observed in the diversity index between the two plant species (Fig. 3). Two sample plots were located on semi-shady and shady slopes, respectively, where a few shrubs were distributed. The coverage of $R$. pseudoacacia was higher than that of $P$. tabuliformis ( $75 \%$ and $40 \%$, respectively) (Fig. 3a). By contrast, the Shannon-Wiener index of $R$. pseudoacacia was higher than that of $P$. tabuliformis 
(Fig. 3b). Correspondingly, the Pielou index of $R$. pseudoacacia was higher than that of P. tabuliformis (Fig. 3c). The higher the Simpson index, the less obvious the status of the herb and vice-a-versa. The Simpson index of $R$. pseudoacacia was lower than that of P. tabuliformis (Fig. 3d).

Table 2. Characteristic of main plant species undergrowth vegetation

\begin{tabular}{|c|c|c|c|c|c|c|c|}
\hline Sample & $\begin{array}{c}\text { Litter } \\
\text { thickness } \\
\text { (cm) }\end{array}$ & $\begin{array}{c}\text { Max water } \\
\text { holding capacity } \\
\left(\mathrm{t} \cdot \mathbf{h m}^{-2}\right)\end{array}$ & $\begin{array}{c}\text { Mas specific } \\
\text { retention }(\%)\end{array}$ & $\begin{array}{l}\text { Natural moisture } \\
\text { content }\left(\mathrm{g} \cdot \mathrm{cm}^{-3}\right)\end{array}$ & $\begin{array}{c}\text { Natural } \\
\text { moisture } \\
(\%)\end{array}$ & $\begin{array}{l}\text { Storage } \\
\text { capacity } \\
\left(\mathrm{t} \cdot \mathrm{hm}^{-2}\right)\end{array}$ & $\begin{array}{c}\text { Modified } \\
\text { interception } \\
\left(\mathbf{t} \cdot \mathbf{h m}^{-2}\right)\end{array}$ \\
\hline R. pseudoacacia & 0.8 & 12.87 & 475.50 & 1.68 & 50.00 & 0.77 & 5.41 \\
\hline P. tabuliformis & 1.6 & 8.35 & 273.00 & 4.43 & 165.00 & 1.16 & 6.51 \\
\hline
\end{tabular}
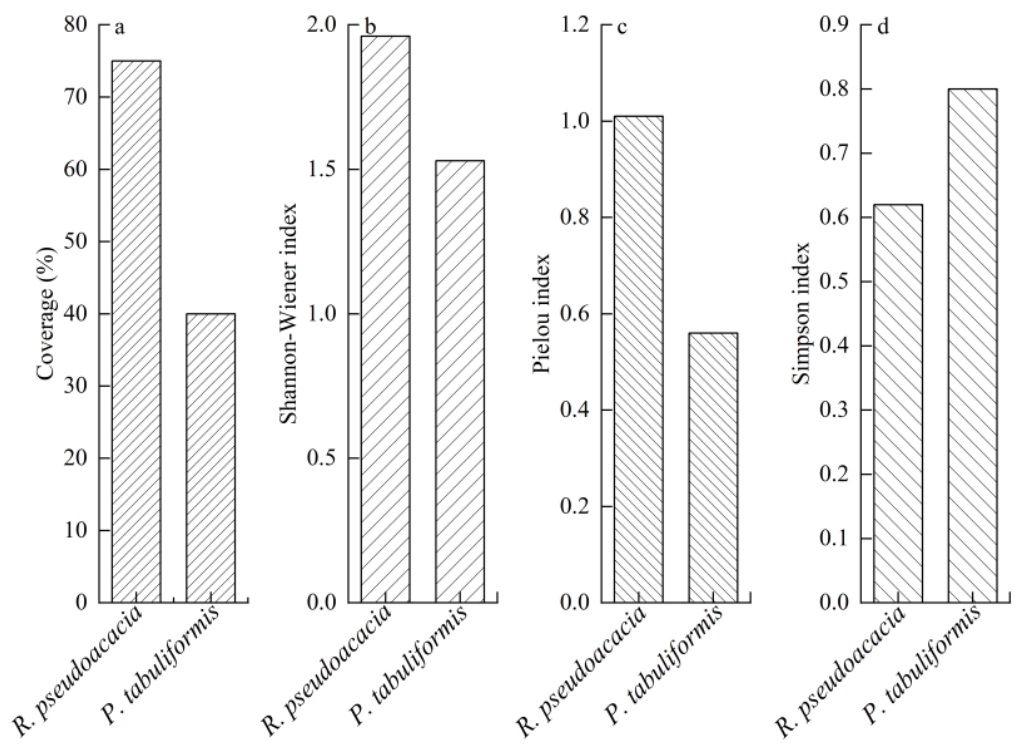

Figure 3. Species diversity indexes of sample plots in wet season

\section{Variation in $S W C$}

In this study, the SWC varied significantly according to the soil layers $(p<0.05)$ (Fig. 4). The SWC of plants decreased with an increase in the depth of soil layers (Fig. 4). Before precipitation, the SWCs of R. psudoacacia and P. tabuliformis with 10$20 \mathrm{~cm}$ and $0-10 \mathrm{~cm}$ soil layers were the highest $(12.42 \%$ and $13.70 \%$, respectively). The SWC of $P$. tabuliformis rapidly decreased from $0-10 \mathrm{~cm}$ to $10-20 \mathrm{~cm}$. The $S W C$ of $R$. psudoacacia increased from $0-10 \mathrm{~cm}$ to $10-20 \mathrm{~cm}$ and then decreased from 10$20 \mathrm{~cm}$ to $40-60 \mathrm{~cm}$ (Fig. 4a). After precipitation, and the $\mathrm{SWC}$ in case of $R$. pseudoacacia decreased gradually from the $0-10 \mathrm{~cm}$ soil layer to the $40-60 \mathrm{~cm}$ soil layer compared with that of P. tabuliformis (Fig. 4b). Because of precipitation, the SWCs of $0-10 \mathrm{~cm}$ and $10-20 \mathrm{~cm}$ layers were the highest and were saturated in case of $R$. pseudoacacia ( $18.93 \%$ and $17.23 \%$, respectively), which may be related to soil texture and rainfall intensity. The SWC of the $20-40 \mathrm{~cm}$ soil layer was the same of $R$. pseudoacacia with an average of $15.80 \%$. In case of $R$. pseudoacacia, the SWC of the $40-60 \mathrm{~cm}$ soil layer considerably decreased, which was dramatically lower than that of the $0-10 \mathrm{~cm}$ soil layer. This was because of the characteristics of the water uptake strategy by the roots of $R$. pseudoacacia. For $P$. tabuliformis, the SWC increased with 
increasing depth in the 30-60 cm soil layers, and decreased in the 10-30 cm (Fig. 4b), which values were similar to that in the upper layer $(0-10 \mathrm{~cm})$, decreased $(10-30 \mathrm{~cm})$ and increased $(30-60 \mathrm{~cm})$ by $18 \%-19 \%$. As the roots of $R$. pseudoacacia are deeper than those of $P$. tabuliformis, the overall variation in the SWC for $R$. pseudoacacia was significantly lower than that for $P$. tabuliformis before and after precipitation.
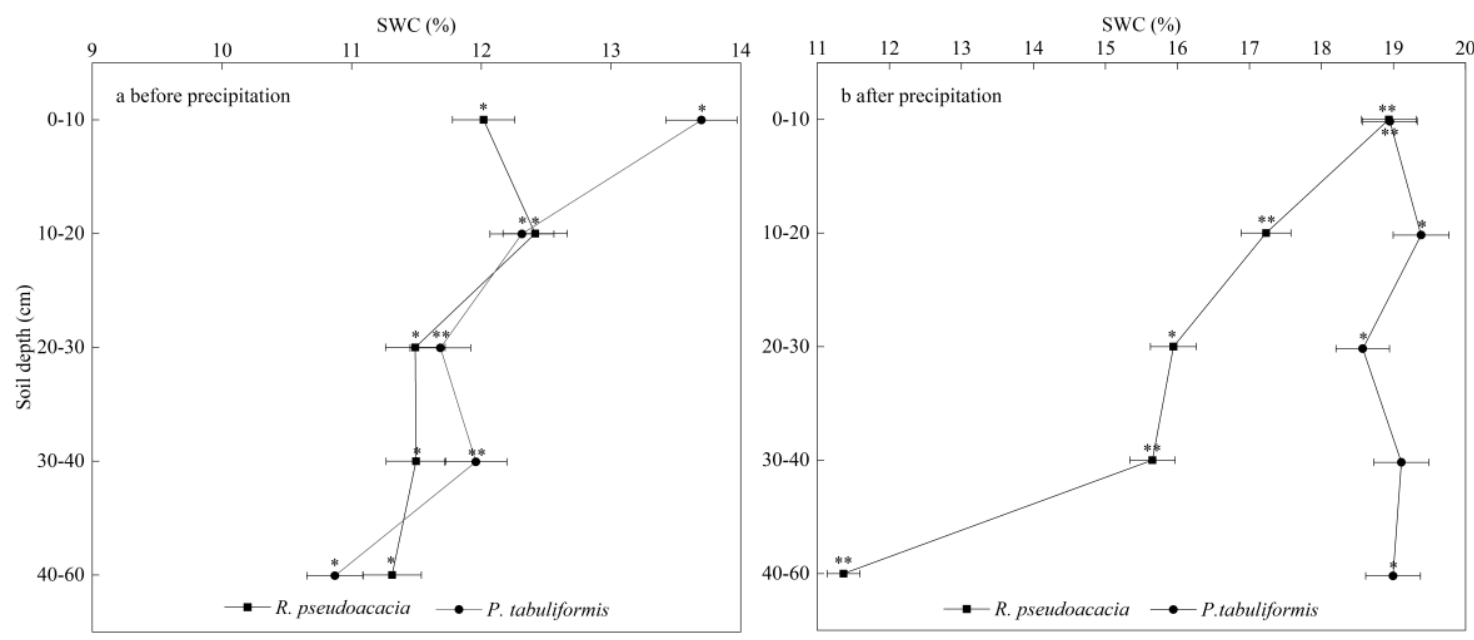

Figure 4. The mean ( \pm S.D.) SWC of R. pseudoacacia and P. tabuliformis in the soil profile before $(a)$ and after $(b)$ precipitation. SWC - soil water content. ** indicate $p<0.01 ; *$ indicate $p<0.05$

\section{Isotopic variations in xylem water, soil water, and precipitation}

We collected total precipitation samples in August 2020 after each rainfall. In addition, seven precipitation events were involved in the analysis of isotopic variation of precipitation samples. Based on the $\delta \mathrm{D}$ and $\delta^{18} \mathrm{O}$ values, the local meteoric water line (LMWL: $\delta \mathrm{D}=6.42 \delta^{18} \mathrm{O}-4.66, \mathrm{R}^{2}=0.95$ ) was determined, in which the intercept and slope were lower than those in the global meteoric water line (GMWL: $\delta \mathrm{D}=8 \delta^{18} \mathrm{O}$ + 10) (Craig, 1961) (Fig. 5). The $\delta^{2} \mathrm{H}$ and $\delta^{18} \mathrm{O}$ values for xylem water and soil water (except for individual points) were below the LMWL and GMWL, indicating that the isotopic constitutions of precipitation exhibited a certain degree of fractionation and evaporation during soil water collection and the water infiltration process. The isotopic values of soil water varied considerably in the course of sampling; the $\delta^{2} \mathrm{H}$ value ranged from $-100.61 \%$ to $-56.32 \%$ with a mean value of $-82.03 \%$, and the $\delta^{18} \mathrm{O}$ value ranged from $-13.88 \%$ to $-7.28 \%$ with an average value of $-11.01 \%$. Moreover, the isotopic values of xylem water were below the LWML values and were similar to those of the soil water, suggesting that xylem water was principally procured from various soil layers. The $\delta^{2} \mathrm{H}$ value for xylem water ranged from $-80.18 \%$ o to $-84.55 \%$ with an average value of $-83.09 \%$, and the $\delta^{18} \mathrm{O}$ value ranged from $-9.66 \%$ to $-10.41 \%$ with a mean value of $-10.13 \%$. The isotopic values of natural spring water were similar to the LMWL and GMWL values. These values were steady $(\delta \mathrm{D}$ was $-63.36 \pm 0.27 \%$, and $\delta^{18} \mathrm{O}$ was $-8.53 \pm 0.14 \%, \mathrm{n}=6$ ) across the sampling periods and were conspicuously different from those of precipitation $\left(\delta \mathrm{D}\right.$ was $-72.13 \pm 0.19 \%$, and $\delta^{18} \mathrm{O}$ was $-10.44 \pm 1.61 \%$ o, $n=6$ ), which suggested that the constitution of natural spring water probably altered according to the rainfall. 


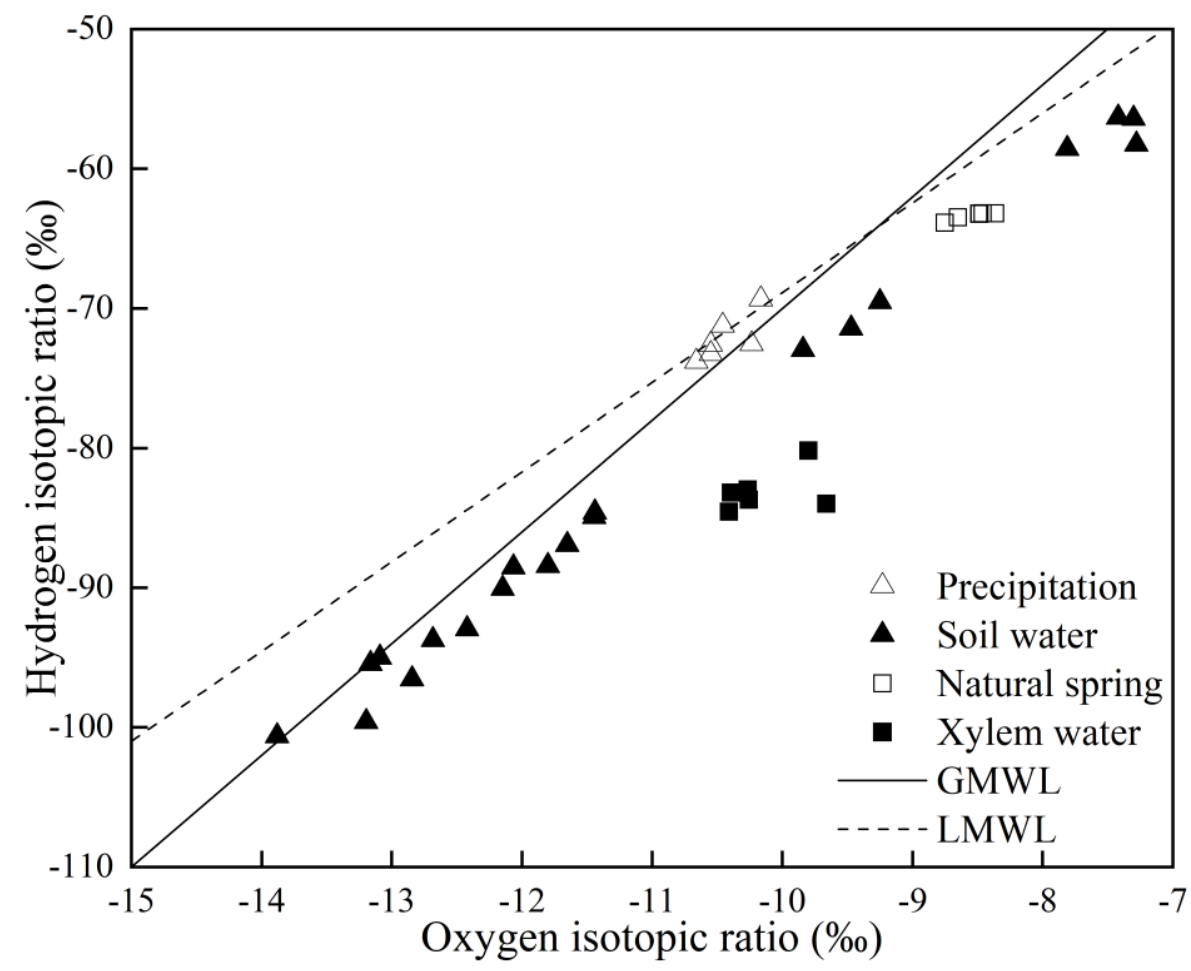

Figure 5. The relationship isotopic values between precipitation, soil water, natural spring and xylem water. The GMWL indicates the global meteoric water line $\left(\delta D=8 \delta^{18} O+10\right)$. LMWL indicates the local meteoric water line $\left(\delta D=6.42 \delta^{18} \mathrm{O}-4.66\right)$ in 2020

\section{Isotopic variation of different trees species}

As per our findings, evaporation and precipitation apparently influenced the soil water in the context of isotopic formation (Fig. 6). The isotopic ratio of soil water in the 20-70 $\mathrm{cm}$ soil layer clearly varied because of evaporative enrichment before precipitation (Fig. 6-I; Fig. 6-III); however, this effect was more obvious after precipitation (Fig. 6- II; Fig. $6-I V)$. Before and after precipitation, the $\delta \mathrm{D}$ and $\delta^{18} \mathrm{O}$ values exhibited an increasing trend with increasing soil depth, with the exception of the soil water in 10-20 cm deep soil layer in case of $P$. tabuliformis. Before precipitation, the $\delta^{2} \mathrm{H}$ and $\delta^{18} \mathrm{O}$ values for $P$. tabuliformis soil water were greater than those for $R$. pseudoacacia soil water; however, after precipitation, these values for $R$. pseudoacacia soil water were greater than those for $P$. tabuliformis soil water. The $\delta^{2} \mathrm{H}$ and $\delta^{18} \mathrm{O}$ values of natural spring water were constant before and after precipitation $\left(\delta^{18} \mathrm{O}-8.50 \%\right.$ and $\delta \mathrm{D}-63.19 \%$ o before precipitation; $\delta^{18} \mathrm{O}$ $-8.59 \%$ and $\delta \mathrm{D}-63.22 \%$ after precipitation) during sampling. However, these values decreased with the events of precipitation in case of groundwater.

Using the method of direct correlation comparison, the $\delta^{2} \mathrm{H}$ and $\delta^{18} \mathrm{O}$ values of xylem water and the potential water source were compared. If the isotopic value of xylem water of a tree species was in the same area of intersects as that of a potential water source, it was considered that this tree used that particular water source (Wang et al., 2013). The intersection points of xylem water of the two species of trees and the $\delta \mathrm{D}$ and $\delta^{18} \mathrm{O}$ variation curves of each potential water source were different before and after precipitation, indicating that the two types of trees used different types of water source before and after precipitation. 
Before precipitation, the $\delta^{2} \mathrm{H}$ and $\delta^{18} \mathrm{O}$ variation curve for $R$. pseudoacacia xylem water and soil water had an intersection at 20-30, 30-40, and 40-50 cm, indicating that $R$. pseudoacacia mainly absorbed water from the $20-50 \mathrm{~cm}$ deep soil layer. Nevertheless, isotopic curves of $R$. pseudoacacia xylem water and soil water had an intersection at 20$30 \mathrm{~cm}$ after precipitation, indicating that it mainly absorbed water from the $20-30 \mathrm{~cm}$ soil layer. In contrast, the $\delta \mathrm{D}$ and $\delta^{18} \mathrm{O}$ variation curve of $P$. tabuliformis xylem water and soil water had an intersection at 20-30 cm, indicating that $P$. tabuliformis mainly absorbed water from the 20-30 cm soil layer. After precipitation, $P$. tabuliformis mainly absorbed water from the $10-30 \mathrm{~cm}$ soil layer because the isotopic curves of xylem water and soil water had an intersection at 10-20 and 20-30 cm.

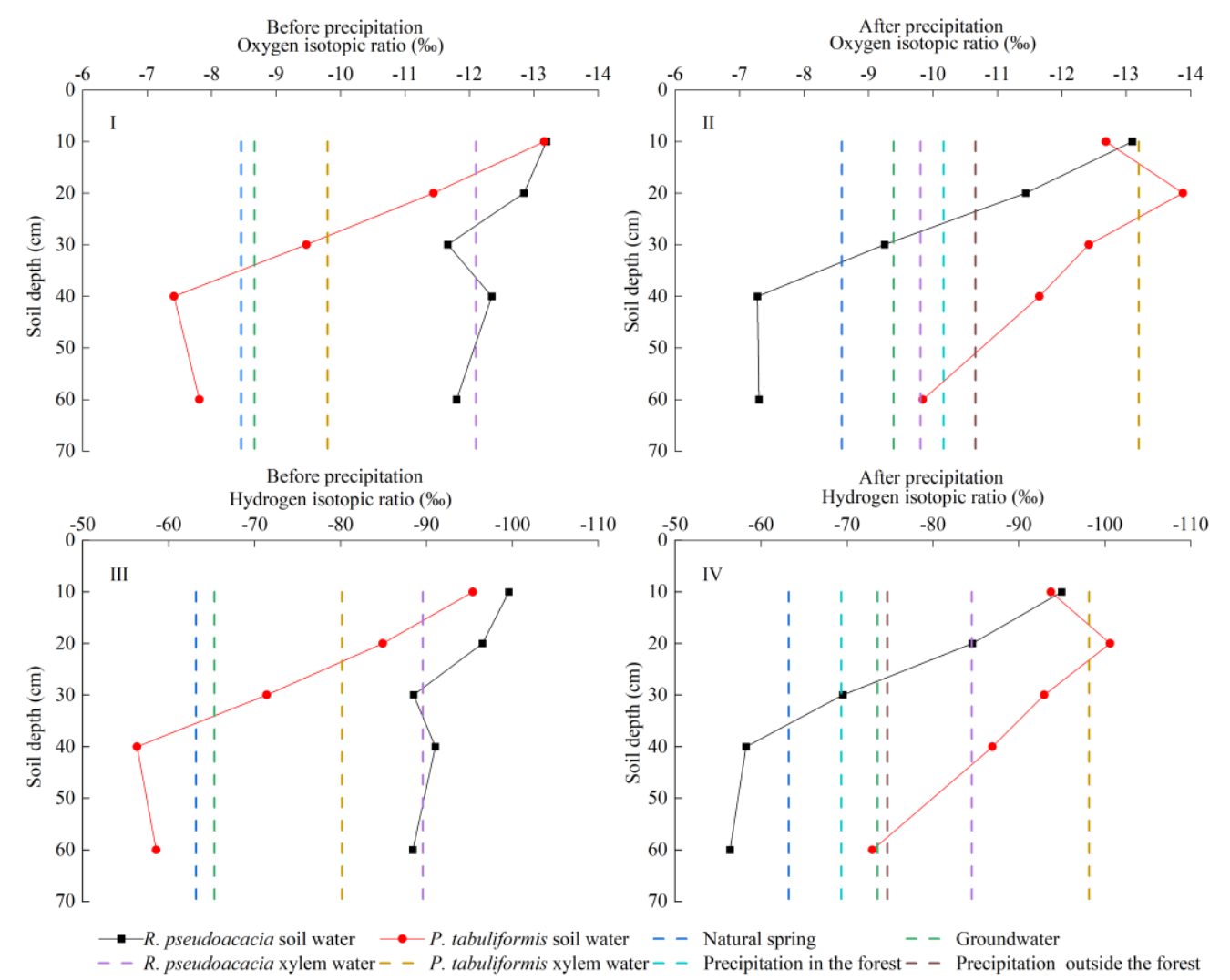

Figure 6. The variation characteristics of $\delta D$ and $\delta^{18} O$ values for $R$. pseudoacacia and $P$. tabuliformis during before and after precipitation

\section{Variations in water sources of trees}

The data analyzed revealed that the two plants species exhibited opposite characteristics of water usage from the water sources (Fig. 7). The results indicated that R. pseudoacacia majorly used water from the $30-40 \mathrm{~cm}$ soil layer (55.6\%) (Fig. 7a) before precipitation. After precipitation, it obtained water from $30-40$ to $20-30 \mathrm{~cm}$ soil layers $(53.15 \%)$ (Fig. 7b). P. tabuliformis obtained water from 20-30 (26.17\%) and 10$20 \mathrm{~cm}$ soil layers $(20.17 \%$ ) (Fig. 7c) before precipitation and from the 10-20 cm soil layer (44.13\%) (Fig. $7 d$ ) after precipitation. Spring water and precipitation exhibited a low contribution percentage in water sources. 

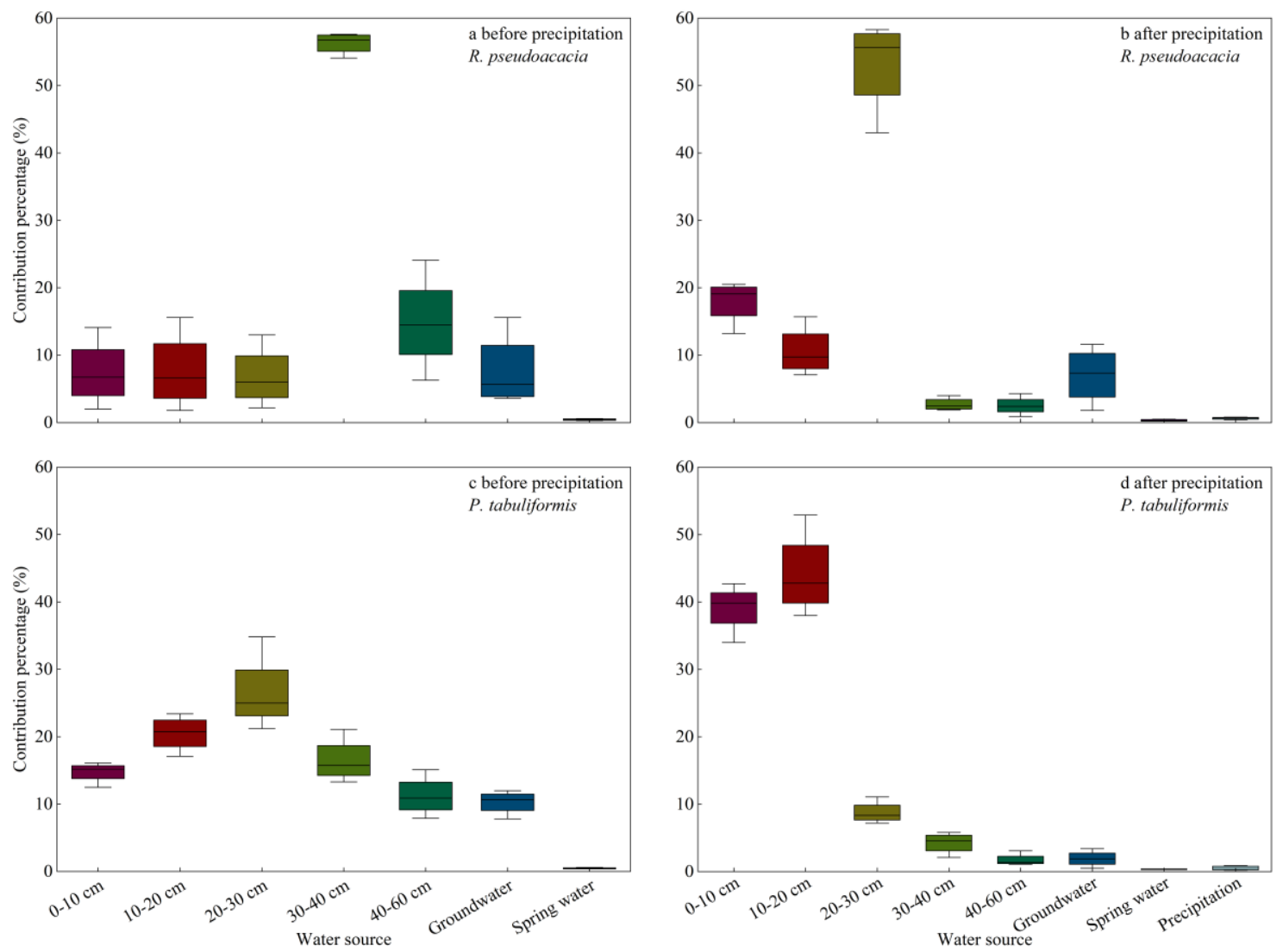

Figure 7. Mean ( \pm S.D.) contribution percentages of the different water source used by $R$. pseudoacacia and $P$. tabuliformis before and after precipitation

\section{Discussion}

\section{Litters and herbs characteristics of R. pseudoacacia and P. tabuliformis}

The litter layer, a kind of loose and porous material, is a vital part of forest ecosystem. The surface energy and its elastic mechanical characteristics have the functions of intercepting rainfall, reducing kinetic energy and regulating runoff. According to the field observation, we found that the litters of $R$. pseudoacacia and $P$. tabuliformis had a strong diversity (Fig. 3). The litter thickness of $R$. pseudoacacia was smaller than that of $P$. tabuliformis. This may be because the litter biomass produced by $R$. pseudoacacia is small, the leaves of this species are small and thin, and the decomposition speed is fast. The large and thick leaves exhibit scattered accumulation; moreover, the decomposition speed of coniferous litter is slow and the surface litter thickness is medium in case of $P$. tabuliformis. Moreover, the water holding capacity and specific retention of litter in case of broadleaf tree species are higher than those in case of conifer species. Conifer litter contains more oil, and its water holding capacity and specific retention are lower than those of broadleaf litter. Our results are consistent with a study by Wang (2000). The findings of other litter variables (natural moisture content, natural moisture, storage capacity and modified interception) in case of these two plant species were consistent with those by Juan et al. (2009). Whether the modified interception of rainfall or its specific retention, litter helps in preventing significant soil and water loss and plays an important role in soil and water conservation. 
The diversity of herb can reflect the relationship between environment and plant community (Dan et al., 2011). Further studies can help in understanding the composition of the species in the community and the development trend. Most of the diversity indices exhibit significant correlation. The Coverage, Shannon-Wiener index, and Pielou index of $R$. pseudoacacia are higher than those of $P$. tabuliformis, whereas the Simpson index of $R$. pseudoacacia is lower than that of $P$. tabuliformis. This is due to the impact of litter thickness on ground because precipitation can reach the surface soil more easily through thin litter layer (Chen et al., 2018). It is beneficial to the growth of herb on the ground surface. Moreover, it is indicated that the herbaceous of broadleaf plants within the broadleaved forest have a higher complex of the community than coniferous plants (Fig. 3), which also contributes to the accumulation of soil water.

\section{SWC and isotopic characteristics of potential water source}

Plants use water from different sources on a landscape level. The potential ecological effects of tree water-use include changes in structure and chemical and physical properties of soil (Iekler et al., 2021; Keyimu et al., 2021). Groundwater and soil water, originating from precipitation, are the vital water sources of plants (Alessio et al., 2010). The different distribution characteristics of rainfall have instant effect on SWC and isotopic formations (Bowling et al., 2016). In this study, the isotopic formations of precipitation, soil water, and xylem water varied with the change in sampling period. The intercept and slope of the GMWL $\left(\delta^{2} \mathrm{H}=8 \delta^{18} \mathrm{O}+10\right)$ were higher than those of the LMWL $\left(\delta^{2} \mathrm{H}=6.42 \delta^{18} \mathrm{O}-4.66\right.$ ) (Fig. 5), and the vast variation in $\delta^{2} \mathrm{H}$ and $\delta^{18} \mathrm{O}$ values of precipitation indicated that atmospheric water vapor had diverse levels of fractionation with the increasing amount of rainfall, which can be conducted that water vapor transport in the atmospheric cycle had a strong evaporation (Liu et al., 2018).

Sun et al. (2019) suggested that the values of oxygen and hydrogen isotopes in rainfall had strong spatial variations around Shanxi. The extents of fractionation for $\delta^{2} \mathrm{H}$ and $\delta^{18} \mathrm{O}$ were dramatically different in the growing seasons due to the rainfall events (Sun et al., 2019). Generally, a large amount of isotopic formation enrichment occurred in the drought period than in the wet period because of intense evaporation of aqueous vapor in the drought period (Uchida et al., 2003). Additionally, the $\delta^{2} \mathrm{H}$ and $\delta^{18} \mathrm{O}$ values of soil water continuously change after rainfall because the water in soil layers experience piston flowing, which preferentially replaces existing water and constantly push the water down (Allison, 1982; Braud et al., 2009; Gazis and Feng, 2004). The $\delta^{2} \mathrm{H}$ and $\delta^{18} \mathrm{O}$ values of soil water were below the LMWL, demonstrating a phenomenon of isotopic concentration in the process of precipitation infiltration. The $\delta^{2} \mathrm{H}$ and $\delta^{18} \mathrm{O}$ isotopic compositions of soil water in case of $R$. pseudoacacia in wet season before precipitation were more negative than those after precipitation. However, opposite result was obtained in case of $P$. tabuliformis. This was because of the direct effect of rainfall on soil water; additionally, rainfall had a sparser isotopic formation in the water in the region of drought soil (Jones et al., 2000; Onac et al., 2008). Meanwhile, the diversity of herb and water holding capacity of $R$. pseudoacacia were more abundant and higher than those of P. tabuliformis (Table 2; Fig. 3); thus, $R$. pseudoacacia can acquire more $\mathrm{D}$ and $\mathrm{O}$ isotopes than $P$. tabuliformis after precipitation, and reduced surface runoff occurred. The isotopic values of soil water in 20-40 cm layer in cases of $R$. pseudoacacia and P. tabuliformis were higher than those in 0-20 cm layer, whereas the isotopic formation in $20-40 \mathrm{~cm}$ soil layer significantly changed, especially before and after precipitation. This would lead to the notable effects of rainfall on evaporation and recharge. 
The $\delta^{2} \mathrm{H}$ and $\delta^{18} \mathrm{O}$ isotopic compositions in water in 40-60 $\mathrm{cm}$ soil layers exhibited minor changes compared with those in 0-20 and 20-40 cm soil layers because of poor evaporation. Our results were consistent with the findings of Máguas et al. (2011), who defined that the soil water isotopic enrichment occurred in the $0-10 \mathrm{~cm}$ soil layer with low SWC and the isotopic values for deep soil layer water were comparatively more negative. White and Smith (2013) identified that evaporation significantly affected the 0-10 cm soil layer with increasing soil depth. Liu et al. (2020) demonstrated that with the increasing soil depths, the evaporation effect gradually weakened, the $0-10 \mathrm{~cm}$ soil layer water was dramatically changed because of strong evaporation fractionation. The isotopic values of natural spring water exhibited slight change before and after rainfall, which were distributed under the LMWL and GMWL. These values were considered to be relatively stable in the wet period. As spring water was situated at deeper soil layers and was recharged by rainfall, it was impossible to get it influenced by the changes in the surroundings. These findings were consistent with the studies by Liu et al. (2018) and Perrin et al. (2003).

\section{Analysis of water uptake strategies}

The two species analyzed in this study had different water sources; moreover, the findings suggested that the usage ratios of the water sources were different. The features of water usage by $R$. pseudoacacia and $P$. tabuliformis were different. $R$. pseudoacacia mainly obtained water from the $30-40 \mathrm{~cm}$ soil layer before precipitation because the 0 $20 \mathrm{~cm}$ soil layer was lacking water, leading to plants quickly integrated photosynthates into the below $20 \mathrm{~cm}$ soil layer, and further shifted its water uptake to the $20-30 \mathrm{~cm}$ soil layer after precipitation (Chang et al., 2019). In addition, $R$. pseudoacacia did not obtain water from spring water before and after precipitation. In contrast, $P$. tabuliformis predominantly obtained water from the $10-30 \mathrm{~cm}$ soil layers before precipitation and from the $0-20 \mathrm{~cm}$ soil layer after precipitation. The water usage strategies of $R$. pseudoacacia and $P$. tabuliformis may had a relation with their root length, root vitality, and root density (Ward et al., 2013). Our findings indicated that $R$. pseudoacacia had a strong taproot system and the lateral roots of $P$. tabuliformis were widely distributed in 0-20 cm soil layers. These results are consistent with those by Liu et al. $(2019,2020)$.

The SWC in $0-10 \mathrm{~cm}$ soil layer was low in the wet season before precipitation. To maintain normal physiological activity and transpiration, $R$. pseudoacacia mainly obtained water from the relatively stable $30-40 \mathrm{~cm}$ soil layer. This indicated that when the water in $0-10 \mathrm{~cm}$ soil layer was adequate, $R$. pseudoacacia chiefly obtained water from the upper soil through the lateral roots containing several root hairs. To maintain regular growth, it extracted water from the $30-40 \mathrm{~cm}$ soil layer to decrease energy loss (Ogle and Reynolds, 2004). The phenomenon of water uptake strategies as per the increasingly changing ambient conditions is termed as "plasticity dimorphic root system" (Liu et al., 2015). These different water sources of $P$. tabuliformis might be because of the varying water distribution. Several studies have reported that $P$. tabuliformis preferred using water from shallower soil in case of events that the increased of soil water (Tang et al., 2018). Plants rarely obtain water from multiple soil layers in the wet period. They adjust their water uptake patterns to adapt to the changes in SWC (Asbjornsen et al., 2007). Liu et al. (2015) showed that when the SWC was abundant, shallow-rooted plants developed could obtain surface soil water easily. When SWC in the surface layer was poor, the ecological plasticity helped trees in obtaining water from deeper soil layers (Li et al., 2006; West et al., 2008). In addition, the 
different lifestyles of these plant species led to diverse water uptake strategies. $R$. pseudoacacia and P. tabuliformis exhibited better ecological plasticity by changing the root activity as per altered water availability. This indicated that these trees exhibited an effective adaptability with the changing ecohydrological conditions.

When the water in all soil layers was less, $R$. pseudoacacia used the water from the $30-40 \mathrm{~cm}$ soil layer to abate the energy expenditure, it had a long distance of water transportation if it extracted water from $40-60 \mathrm{~cm}$ or more deeper soil depth (Carolina and North, 2002). However, a new response developed in $R$. pseudoacacia when the SWC in all soil depths was high after precipitation. $R$. pseudoacacia used its developed taproot system to access water in middle and shallow soil layers. The evaporation cannot readily influence water in these soil layers; thus, the water in these soil layers can be maintained at a relatively stable level. A stable and abundant water supply from middle soil layers might content a great ratio of transpiration wastage by $R$. pseudoacacia (Asbjornsen et al., 2008; Liu et al., 2017). Meanwhile, since the $0-10 \mathrm{~cm}$ soil layer exhibited strong evaporation, $R$. pseudoacacia obtained water from deeper soil layers to maintain transpiration before precipitation. Therefore, it could be presumed that the deep-rooted plants easily obtained water from relatively deeper soil layers (Zhang et al., 2018). The water usage model allowed plants to flexibly change water sources among surface and deep soil layers, which was favorable for plants growing in the Loess Plateau area (Dawson and Pate, 1996). Overall, the results indicated that $P$. tabuliformis obtained water from the $0-30 \mathrm{~cm}$ soil layer in the growing period. During water shortage (before precipitation), $P$. tabuliformis was in the early phases of development, and water extracted from the $10-30 \mathrm{~cm}$ soil layer was used for transpiration. However, after precipitation, uptake of water from the $30-40 \mathrm{~cm}$ soil layer stopped because of evaporative requirement exceeding water input; the plants absorbed water from the 0-20 cm soil layer using horizontally expanded roots (Liu et al., 2017; West et al., 2008). Trees grown in characteristic arid area may have superior survival and are competitive, which can switch water sources to be able to use the most of water to assure their normal physiological activity (Li et al., 2006; Liu et al., 2017). IsoSource model results indicated that water uptake patterns and sources of these two typical broadleaf and coniferous trees ( $R$. pseudoacacia and $P$. tabuliformis) distributed in the Loess Plateau mountain were flexible. Therefore, these two typical tree species exhibited a stronger adaption and better coexistence characteristics during the periods of water shortage and drought. Further long-term studies should investigate root biomass, characteristic variations affecting root activities, and the changes in stable isotopes during different periods.

\section{Conclusions}

In this study, we used stable isotope techniques to determine water sources of broadleaf and coniferous trees distributed in the Loess Plateau mountain area in the wet period. Precipitation played a significant role in the isotope composition. The $\delta^{2} \mathrm{H}$ and $\delta^{18} \mathrm{O}$ isotopic values of water in the $40-60 \mathrm{~cm}$ soil layer exhibited significant infiltration concentration than those in the $0-10 \mathrm{~cm}$ soil layer. $P$. tabuliformis obtained water majorly from 10-20 and 20-30 cm soil layers before precipitation. $R$. pseudoacacia chiefly obtained water from the $30-40 \mathrm{~cm}$ soil layer in case of poor SWC and further changed its water source to the $20-30 \mathrm{~cm}$ soil layer to maintain transpiration after precipitation. $P$. tabuliformis predominantly obtained water from the $0-20 \mathrm{~cm}$ soil layer 
after rainfall. Together, these species can fully use limited water in the Loess Plateau area. Meanwhile, our finding showed that the standing vegetation of broadleaf plant had the higher complex of the community than conifer plant. Hence, we can deduce that $R$. pseudoacacia and $P$. tabuliformis are appropriately adapted to arid conditions (the Loess Plateau area) and can rapidly adjust their water uptake strategies in case of water shortage. In this study, we observed that $R$. pseudoacacia and P. tabuliformis cannot uptake water from deep soil layers before and after precipitation; a large amount of groundwater was preserved to maintain growth in dry season when a combination of the two plant species was considered, and the approach can be used to deal with the problem of increasing water scarcity due to climate change. Our study provides management measures by which the two species can be used in combination to effectively solve the survival problems of $P$. tabuliformis and $R$. pseudoacacia by forming a mixed forest in the Loess Plateau mountain area of northern China.

Acknowledgements. This work was supported by the National Natural Science Foundation of China (No. 31901365, 31971644, and 31500523); Innovation project of graduate education in Shanxi Province (No. 2020BY048); technological innovation project of colleges and universities in Shanxi province (No. 201910394); Shanxi provincial outstanding doctoral program for incentive funds for scientific research projects (No. SXYBKY2018032); Fund for introduced talents for Shanxi agricultural university (No. 2018yj09 and 2014yj19). We thank TopEdit (www.topeditsci.com) for its linguistic assistance during the preparation of this manuscript.

\section{REFERENCES}

[1] Alessio, G. A., Lillis, M., Brugnoli, E., Lauteri, M. (2010): Water sources and water-use efficiency in Mediterranean coastal dune vegetation. - Plant Biology 6(3): 350-357.

[2] Allison, G. B. (1982): The relationship between (super 18) $\mathrm{O}$ and deuterium in water in sand columns undergoing evaporation. - Journal of Hydrology 55: 163-169.

[3] Asbjornsen, H., Mora, G., Helmers, M. J. (2007): Variation in water uptake dynamics among contrasting agricultural and native plant communities in the Midwestern U.S. Agriculture Ecosystems \& Environment 121(4): 343-356.

[4] Asbjornsen, H., Shepherd, G., Helmers, M., Mora (2008): Seasonal patterns in depth of water uptake under contrasting annual and perennial systems in the Corn Belt Region of the Midwestern U.S. - Plant \& Soil 3087(1-2): 69-92.

[5] Bai, Y., Han, X., Wu, J., Chen, Z., Li, L. (2004): Ecosystem stability and compensatory effects in the Inner Mongolia grassland. - Nature 431(7005): 181-4.

[6] Bowling, D. R., Schulze, E. S., Hall, S. J. (2016): Revisiting streamside trees that do not use stream water: can the two water worlds hypothesis and snowpack isotopic effects explain a missing water source? - Ecohydrology 10(1).

[7] Boyer, J., S. (1982): Plant Productivity and Environment. - Science 218: 443-448.

[8] Braud, I., Biron, P., Bariac, T., Richard, P., Canale, L., Gaudet, J. P., Vauclin, M. (2009): Isotopic composition of bare soil evaporated water vapor. Part I: RUBIC IV experimental setup and results. - Journal of Hydrology 369(1): 1-16.

[9] Caldweli, L. M. M. (2005): Shifts in depth of water extraction and photosynthetic capacity inferred from stable isotope proxies across an ecotone of Juniperus osteosperma (Utah juniper) and Artemisia tridentata (big sagebrush). - Journal of Ecology 93(4): 783793.

[10] Chang, E., Li, P., Li, Z., Xiao, L., Zhao, B., Su, Y., Feng, Z. (2019): Using water isotopes to analyze water uptake during vegetation succession on abandoned cropland on the Loess Plateau, China. - Catena 181: 104095. 
[11] Chen, J., Xu, M., Zou, X., Tao, S., Wang, D., Zhang, J. (2018): Litter layer reserve and water holding capacity of Pinus massoniana in different successional stages in Guiyang. Research of Soil and Water Conservation 25(6): 146-151.

[12] Cheng, X., An, S., Li, B., Chen, J., Lin, G., Liu, Y., Luo, Y., Liu, S., Lin, Y. (2006): Summer rain pulse size and rainwater uptake by three dominant desert plants in a desertified grassland ecosystem in northwestern China. - Plant Ecology 184(1): 1-12.

[13] Craig, H. (1961): Isotopic variations in meteoric waters. - Science 133(3465): 17021703.

[14] Dai, Y., Zheng, X. J., Tang, L. S., Li, Y. (2015): Stable oxygen isotopes reveal distinct water use patterns of two Haloxylon species in the Gurbantonggut Desert. - Plant \& Soil 389(1-2): 73-87.

[15] Dan, F. B. F., Mirotchnick, N., Jain, M., Palmer, M. I., Naeem, S. (2011): Functional and phylogenetic diversity as predictors of biodiversity-ecosystem-function relationships. Ecology 92(8): 1573-1581.

[16] Dawson, T. E., Pate, J. S. (1996): Seasonal water uptake and movement in root systems of Australian phraeatophytic plants of dimorphic root morphology: a stable isotope investigation. - Oecologia 107(1): 13-20.

[17] Deng, K., Yang, S., Lian, E., Li, C., Yang, C., Wei, H. (2016): Three Gorges Dam alters the Changjiang (Yangtze) river water cycle in the dry seasons: evidence from H-O isotopes. - Science of the Total Environment 562(15): 89-97.

[18] Dunkerley, D. (2015): Percolation through leaf litter: what happens during rainfall events of varying intensity? - Journal of Hydrology 525: 737-746.

[19] Evaristo, J., Mcdonnell, J. J., Scholl, M. A., Bruijnzeel, L. A., Chun, K. P. (2016): Insights into plant water uptake from xylem-water isotope measurements in two tropical catchments with contrasting moisture conditions. - Hydrological Processes 30.

[20] Flanagan, L. B., Ehleringer, J. R., Marshall, J. D. (2010): Differential uptake of summer precipitation among co-occurring trees and shrubs in a pinyon-juniper woodland. - Plant Cell \& Environment 15(7): 831-836.

[21] Gannes, L. Z., Rio, C. M. M. D., Koch, P. L. (1998): Natural abundance variations in stable isotopes and their potential uses in animal physiological ecology. - Comparative Biochemistry \& Physiology Part A Molecular \& Integrative Physiology 119(3): 725-737.

[22] Gao, X., Wu, P., Zhao, X., Shi, Y., Wang, J., Zhang, B. (2011): Soil moisture variability along transects over a well-developed gully in the Loess Plateau, China. - Catena 87(3): 357-367.

[23] Gazis, C., Feng, X. (2004): A stable isotope study of soil water: evidence for mixing and preferential flow paths. - Geoderma 119(1-2): 97-111.

[24] Gurumurthy, G. P., Balakrishna, K., Tripti, M., Riotte, J., Audry, S., Braun, J. J., Lambs, L., Shankar, H. N. U. (2015): Sources of major ions and processes affecting the geochemical and isotopic signatures of subsurface waters along a tropical river, Southwestern India. - Environmental Earth Sciences 73(1): 333-346.

[25] Heras, M. D. L., Espigares, T., Merino-Martín, L., Nicolau, J. M. (2011): Water-related ecological impacts of rill erosion processes in Mediterranean-dry reclaimed slopes. Catena 84(3): 114-124.

[26] Ianovici, N., Batalu, A., Hriscu, D., Datcu, A. D. (2020): Phytomonitoring study on intra urban variations of leaves of some evergreen and deciduous trees. - Ecological Indicators 114: 106313.

[27] Iekler, M., Erkan, S., Tutus, A. (2021): A study on the effects of potassium borohydride in pulp and paper production from black locust (Robinia pseudoacacia L.) wood. Turkish Journal of Forestry/Türkiye Ormancıllk Dergisi 22(1): 33-37.

[28] Jackson, P. C., Meinzer, F. C., Mercedes, B., Guillermo, G., Augusto, F., Rundel, P. W., Linda, C., Erica, I., Fabio, C. (1999): Partitioning of soil water among tree species in a Brazilian Cerrado ecosystem. - Tree Physiology (11): 717-724. 
[29] Jones, I. C., Banner, J. L., Humphrey, J. D. (2000): Estimating recharge in a tropical karst aquifer. - Water Resources Research 36(5): 1289-1299.

[30] Juan, X. U., Xin-Xiao, Y. U., Cai-Yun, X. I. (2009): Hydrological effects of forest litters and soil in ming tombs forest farm. - Journal of Soil \& Water Conservation 23(3): 189193.

[31] Kambatuku, J. R., Cramer, M. D., Ward, D. (2013): Overlap in soil water sources of savanna woody seedlings and grasses. - Ecohydrology 6(3): 464-473.

[32] Keyimu, M., Li, Z., Fu, B. J., Chen, W., Lu, Y. (2021): Spatial differences in the radial growth responses of black locust (Robinia pseudoacacia Linn.) to climate on the Loess Plateau, China. - Dendrochronologia 68.

[33] Knapp, A. K., Briggs, J. M., Koelliker, J. K. (2001): Frequency and extent of water limitation to primary production in a mesic temperate grassland. - Ecosystems 4(1): 1928.

[34] Busato, L., Boaga, J., Perri, T. M., Majone, B., Bellin, A. (2019): Hydrogeophysical characterization and monitoring of the hyporheic and riparian zones: the Vermigliana Creek case study. - Science of the Total Environment 648: 1105-1120.

[35] Li, S. G., Tsujimura, M., Sugimoto, A., Sasaki, L., Yamanaka, T., Davaa, G., Oyunbaatar, D., Sugita, M. (2006): Seasonal variation in oxygen isotope composition of waters for a montane larch forest in Mongolia. - Trees 20(1): 122-130.

[36] Li, B., Chen, Y., Shi, X., Chen, Z., Li, W. (2013): Temperature and precipitation changes in different environments in the arid region of northwest China. - Theoretical \& Applied Climatology 112(3): 589-596.

[37] Liu, W., Wang, P., Li, J., Liu, W., Li, H. (2015): Plasticity of source-water acquisition in epiphytic, transitional and terrestrial growth phases of Ficus tinctoria. - Ecohydrology 7(6): 1524-1533.

[38] Liu, Z., Yu, X., Jia, G., Jia, J., Lou, Y., Lu, W. (2017): Contrasting water sources of evergreen and deciduous tree species in rocky mountain area of Beijing, China. - Catena 150: $108-115$.

[39] Liu, Z., Yu, X., Jia, G. (2018): Water utilization characteristics of typical vegetation in the rocky mountain area of Beijing, China. - Ecological Indicators 91: 249-258.

[40] Liu, Z., Yu, X., Jia, G. (2019): Water uptake by coniferous and broad-leaved forest in a rocky mountainous area of northern China. - Agricultural and Forest Meteorology 265: 381-389.

[41] Liu, Z., Jia, G., Yu, X. (2020): Variation of water uptake in degradation agroforestry shelterbelts on the North China Plain. - Agriculture, Ecosystems \& Environment 287: 106697.

[42] Máguas, C., Rascher, K. G., Martins-Loucao, A., Carvalho, P., Ramos, M., Correia, O., Werner Pinto, C. (2011): Responses of woody species to spatial and temporal ground water changes in coastal sand dune systems. - Biogeosciences 8(99): 3823-3832.

[43] Mei, X., Zhu, Q., Ma, L., Zhang, D., Liu, H., Xue, M. (2018): The spatial variability of soil water storage and its controlling factors during dry and wet periods on loess hillslopes. - Catena 162: 333-344.

[44] Moreno-Gutiérrez, C., Battipaglia, G., Cherubini, P., Huertas, A. D., Querejeta, J. I. (2015): Pine afforestation decreases the long-term performance of understorey shrubs in a semi-arid Mediterranean ecosystem: a stable isotope approach. - Functional Ecology 29(1): 15-25.

[45] Ogle, K., Reynolds, J. F. (2004): Plant responses to precipitation in desert ecosystems: integrating functional types, pulses, thresholds, and delays. - Oecologia 141(2): 282-294.

[46] Onac, B. P., Pace-Graczyk, K., Atudirei, V. (2008): Stable isotope study of precipitation and cave drip water in Florida (USA): implications for speleothem-based paleoclimate studies. - Isotopes Environ Health Stud 44(2): 149-161. 
[47] Perrin, J., Jeannin, P. Y., Zwahlen, F. (2003): Epikarst storage in a karst aquifer: a conceptual model based on isotopic data, Milandre test site, Switzerland. - Journal of Hydrology 279(1-4): 106-124.

[48] Phillips, D. L., Gregg, J. W. (2003): Source partitioning using stable isotopes: coping with too many sources. - Oecologia 136(2): 261-269.

[49] Poot, P., Lambers, H. (2008): Shallow-oil endemics: adaptive advantages and constraints of a specialized root-system morphology. - New Phytologist 178(2): 371-381.

[50] Quesada, A. C., Hodnett, G., M., Breyer, L. M., Santos, A. J. B., Andrade, S., Heloisa, S. M., Miranda, A. C., Lloyd, J. (2008): Seasonal variations in soil water in two woodland savannas of central Brazil with different fire histories. - Tree Physiology 28(3): 405-415.

[51] Romero-Saltos, H., Sternberg, L. D. S. L., Moreira, M. Z., Nepstad, D. C. (2005): Rainfall exclusion in an eastern Amazonian forest alters soil water movement and depth of water uptake. - American Journal of Botany 92(2): 443-455.

[52] Schenk, H. J., Jackson, R. B. (2002): The global biogeography of roots. - Ecological Monographs 72(3): 311-328.

[53] Sun, C., Chen, W., Chen, Y., Cai, Z. (2019): Stable isotopes of atmospheric precipitation and its environmental drivers in the Eastern Chinese Loess Plateau, China. - Journal of Hydrology 581: 124404.

[54] Tang, Y. K., Wu, X., Chen, Y. M., Wen, J., Xie, Y. L., Lu, S. B. (2018): Water use strategies for two dominant tree species in pure and mixed plantations of the semiarid Chinese Loess Plateau. - Ecohydrology 11(4).

[55] Uchida, T., Asano, Y., Ohte, N., Mizuyama, T. (2003): Analysis of flowpath dynamics in a steep unchannelled hollow in the Tanakami Mountains of Japan. - Hydrological Processes 17(2): 417-430.

[56] Wang, Y. M. (2000): Summary of researches on water and soil conservative function of litter in forestland in China. - Journal of Soil Water Conservation.

[57] Wang, H. Y., Liu, T. X., Wang, L., Yao, W. U., Wang, T. S., Tong, X. (2013): Spatial variation of soil moisture content in the dune-meadow ecotone in the Horqin sandy land. - Arid Zone Research 30(3): 438-443.

[58] Wang, J., Bi, H., Sun, Y., Duan, H., Peng, R. (2018): The improved canopy shading model based on the apple intercropping system (case study: Loess Plateau, China). Sustainability 10(10): 3486.

[59] Ward, D., Wiegand, K., Getzin, S. (2013): Walter's two-layer hypothesis revisited: back to the roots! - Oecologia 172(3): 617-630.

[60] Wei, X., Bi, H., Liang, W., Hou, G., Kong, L., Zhou, Q. (2018): Relationship between soil characteristics and stand structure of Robinia pseudoacacia L. and Pinus tabulaeformis Carr. mixed plantations in the Caijiachuan watershed: an application of structural equation modeling. - Forests 9(3): 124.

[61] West, A. G., Hultine, K. R., Sperry, J. S., Bush, S. E., Ehleringer, J. R. (2008): Transpiration and hydraulic strategies in a pion-juniper woodland. - Ecological Applications 18(4): 911-927.

[62] White, J. C., Smith, W. K. (2013): Water sources in riparian trees of the southern Appalachian foothills, USA: a preliminary study with stable isotope analysis. - Riparian Ecology \& Conservation 1: 46-52.

[63] Williams, D. G., Ehleringer, J. R. (2000): Intra- and interspecific variation for summer precipitation use in pinyon-juniper woodlands. - Ecological Monographs 70(4): 517-537.

[64] Wood, W. W. (2011): Source of paleo-groundwater in the Emirate of Abu Dhabi, United Arab Emirates: evidence from unusual oxygen and deuterium isotope data. Hydrogeology Journal 19(1): 155-161.

[65] Wu, Y., Zhou, H., Zheng, X. J., Li, Y., Tang, L. S. (2015): Seasonal changes in the water use strategies of three co-occurring desert shrubs. - Hydrological Processes 28(26): 62656275 . 
[66] Wu, H., Li, X. Y., Jiang, Z., Chen, H., Zhang, C., Xiong, X. (2016): Contrasting water use pattern of introduced and native plants in an alpine desert ecosystem, Northeast Qinghai-Tibet Plateau, China. - Science of the Total Environment 542(2): 182-191.

[67] Xu, Yi, Yang, Dou (2019): Using stable hydrogen and oxygen isotopes to distinguish the sources of plant leaf surface moisture in an urban environment. - Water 11(11): 2287.

[68] Xuede, D., Peng, G., Rui, Z., Cheng, L., Xingjian, D., Xiang, N. (2021): Changing characteristics and influencing factors of the soil microbial community during litter decomposition in a mixed Quercus acutissima Carruth. and Robinia pseudoacacia L. forest in Northern China. - Catena 196: 104811.

[69] Yang, H., Auerswald, K., Bai, Y., Han, X. (2011): Complementarity in water sources among dominant species in typical steppe ecosystems of Inner Mongolia, China. - Plant \& Soil 340(s1-2): 303-313.

[70] Yang, Q., Xiao, H. L., Zhao, L. J., Zhou, M. X., Li, C. Z., Cao, S. K. (2010): Stable isotope techniques in plant water sources: a review. - Sciences in Cold and Arid Regions 2(2): 112-122.

[71] Zhai, Y., Guo, Y., Zhou, J., Guo, N., Wang, J., Teng, Y. (2014): The spatio-temporal variability of annual precipitation and its local impact factors during 1724-2010 in Beijing, China. - Hydrological Processes 28(4): 2192-2201.

[72] Zhan, L., Chen, J., Li, L., Xin, P. (2019): Plant water use strategies indicated by isotopic signatures of leaf water: observations in southern and northern China. - Agricultural and Forest Meteorology 276-277: 107624.

[73] Zhang, Z., Song, S., Wu, H., Yu, X., Zhang, Q. (2011): Factors affecting soil erosion in Beijing mountain forestlands. - African Journal of Biotechnology 10: 17134-17141.

[74] Zhang, Y., Wei, L., Wei, X., Liu, X., Shao, M. (2018): Long-term afforestation significantly improves the fertility of abandoned farmland along a soil clay gradient on the Chinese Loess Plateau. - Land Degradation \& Development 29(10): 3521-3534. 